\title{
Relationships between Species of Dyestuff Precursor and Dyeability in Hair Colouring Made by Enzymatic Oxidation Technique Using Bio-Catechols
}

\author{
Takanori Matsubara' ${ }^{1}$, Chinami Seki ${ }^{2}$, Hidekazu Yasunaga ${ }^{2}$ \\ ${ }^{1}$ Department of Mechanical Engineering, College of Industrial Technology, Amagasaki, Japan \\ ${ }^{2}$ Department of Fibre Science and Engineering, Kyoto Institute of Technology, Kyoto, Japan \\ Email: yasunaga@kit.ac.jp
}

How to cite this paper: Matsubara, T., Seki, C and Yasunaga, H. (2017) Relationships between Species of Dyestuff Precursor and Dyeability in Hair Colouring Made by Enzymatic Oxidation Technique Using Bio-Catechols. American Journal of Plant Sciences, 8, 1471-1483. https://doi.org/10.4236/ajps.2017.86101

Received: April 19, 2017

Accepted: May 24, 2017

Published: May 27, 2017

Copyright ( 92017 by authors and Scientific Research Publishing Inc. This work is licensed under the Creative Commons Attribution International License (CC BY 4.0).

http://creativecommons.org/licenses/by/4.0/

\section{(c) (i) Open Access}

\begin{abstract}
In the study, hair colouring by utilising enzymatic oxidation of nine species of bio-catechols, which are biobased materials having the catechol (o-dihydroxybenzene) group, was examined. The bio-catechols used are $(+)$-catechin (Cat), (-)-epicatechin (EC), L-3,4-dihydroxyphenylalanine (DOPA), hematoxylin (HX), brazilin (BZ), rosmarinic acid (RA), caffeic acid (CA), chlorogenic acid (ChA) or ellagic acid (EA). The dyeability of human white hair samples dyed by two kinds of dyeing methods using the bio-catechols was compared. First one is dyeing hair during the enzymatic oxidation of a bio-catechol dye precursor in a dye solution (simultaneous oxidation dyeing method). Second one is dyeing hair by oxidising enzymatically the precursor on hair, which is pre-treated with a bio-catechol solution (post-oxidation dyeing method). The results show that the bio-catechols except EA are oxidised to give colourants and Cat, EC, DOPA, HX and BZ are available for hair dyeing. Overall, the dyeability of simultaneous oxidation dyeing method is higher than that of post-oxidation one. The colour of the hair dyed by simultaneous method is yellowish brown for Cat or EC, grey for DOPA, dark yellowish brown for HX or reddish brown for BZ, respectively. The most vivid or deepest colour of dyed hair is obtained by dyeing with Cat or HX, respectively, in the simultaneous technique. It was found that the bio-catechols having chroman (3, 4-dihydro-2 $H$-1-benzopyran) structure in the molecule such as Cat, EC, $\mathrm{HX}$ and $\mathrm{BZ}$ are useful for hair colouring.
\end{abstract}

\section{Keywords}

Bio-Catechol, Hair Dyeing, Dyestuff, Enzymatic Oxidation, Tyrosinase

\footnotetext{
${ }^{1}$ The part of the data of this study were presented at the 13th Asian Textile Conference on 3-6 November 2015 at Geelong, Australia, 7th Research Meeting on Hair Scientists Association on 17 February 2016 at Tokyo, Japan and the Annual Meeting of The Society of Fiber Science and Technology, Japan on 8-10 June 2016 at Tokyo, Japan.
} 


\section{Introduction}

The oxidation dyes for hair dyeing involve risk and give rise to some symptoms according to the circumstances [1] [2]. Therefore, a safer hair dyeing technique is desired to be invented. The safer hair colouring by using biobased materials has been studied by the authors and the catechinone dyes obtained from $(+)$ catechin were found to be applicable to dye human hair [3]. The (+)-catechin is enzymatically or chemically oxidised to form catechinone, which works as a hair dyestuff and dyes hair yellow, orange and reddish brown without skin irritation [3] [4]. The resulting colour of hair and the dyeability depend on dyeing conditions such as the dyestuff concentration, temperature, $\mathrm{pH}$ and the sorts of additives [4]. Especially, the obtained colour differs between types of oxidation methods for $(+)$-catechin. The enzymatically-produced catechinone dyes hair more vivid yellowish brown and chemically-produced catechinone colours hair deeper reddish brown. The colour fastness of the hair dyed with catechinone to washing and light is high enough in practical use [3] [4].

There are four kinds of techniques to dye hair by utilising oxidation of $(+)-$ catechin [5]. They are as follows: 1) Redissolution Dyeing Method: dyeing hair in the dye solution containing the catechinone redissolved, which is preliminarily obtained by the enzymatic oxidation of (+)-catechin; 2) Sequential Dyeing Method: dyeing hair in the dye solution just after the catechinone being formed by the enzymatic reaction; 3) Simultaneous Oxidation Dyeing Method: dyeing hair in solution containing $(+)$-catechin and the dyeing process is accompanied by the enzymatic oxidation; 4) Post-Oxidation Dyeing Method: hair is immersed into $(+)$-catechin solution at the first step and then the hair is treated in another solution containing the enzyme at the second step. The obtained colour of hair dyed with (+)-catechin by the simultaneous enzymatic oxidation dyeing method is deeper than that by the other methods. The hair dyed enzymatically by the post-oxidation dyeing method shows reddish brown.

The catechol ( $o$-dihydroxybenzene) group of $(+)$-catechin is chiefly oxidised to give a chromophore. The oxidation of it plays a vital role in forming the dyestuff and dyeing hair. It is, therefore, expected that biobased materials having the catechol group can work as the dye precursor for hair dyeing. The acquisition of colour variation is also anticipated by using other various biocatechol materials.

Thereupon, the bio-catechols, such as (-)-epicatechin, L-3,4-dihydroxyphenylalanine, hematoxylin, brazilin, rosmarinic acid, caffeic acid, chlorogenic acid and ellagic acid were used to dye hair by the enzymatic simultaneous oxidation dyeing or post-oxidation dyeing techniques in this study. Their dyeability was estimated comparing with that of (+)-catechin and the differences in the dyeability were discussed. The relationships between the species of bio-catechols and the dyeability in hair colouring were studied to understand the characteristics of their chemical structure.

\section{Experimental}

\subsection{Materials}

(+)-Catechin (Cat, $M_{\mathrm{w}}=290.27$, Sigma), $(-)$-epicatechin $\left(\mathrm{EC}, M_{\mathrm{w}}=290.27\right.$, 
Sigma), L-3,4-dihydroxyphenyl-alanine (DOPA, $M_{\mathrm{w}}=190.17$, Nacalai Tesque (NT)), hematoxylin (HX, $\left.M_{\mathrm{w}}=302.28, \mathrm{NT}\right)$, brazilin (BZ, $M_{\mathrm{w}}=280.28, \mathrm{MP}$ Biomedicals), rosmarinic acid (RA, $M_{\mathrm{w}}=360.31$, Carbosynth Limited), caffeic acid $\left(\mathrm{CA}, M_{\mathrm{w}}=180.16\right.$, Tokyo Chemical Industry (TCI)), chlorogenic acid (ChA, $\left.M_{\mathrm{w}}=354.31, \mathrm{TCI}\right)$ and ellagic acid $\left(\mathrm{EA}, M_{\mathrm{w}}=338.19\right.$, TCI) were used as the dyestuff precursors without further purification. Figure 1 shows their chemical structures. Tyrosinase from mushroom $\left(M_{\mathrm{w}}=1.28 \times 10^{5}\right.$ obtained by sedimentation velocity diffusion, $1.33 \times 10^{5}$ by light-scattering measurements and $1.20 \times 10^{5}$ by electrophoresis, Sigma) was used as received. Disodium hydrogen phosphate $\left(\mathrm{Na}_{2} \mathrm{HPO}_{4}, F_{\mathrm{w}}=141.96, \mathrm{NT}\right)$ and sodium dihydrogen phosphate $\left(\mathrm{NaH}_{2} \mathrm{PO}_{4}, F_{\mathrm{w}}=119.98, \mathrm{NT}\right)$ were used as $\mathrm{pH}$ regulators without further purification. Distilled water was used for the preparation of solutions, washing and rinsing. The human hair samples (Mathai Japan, obtained from Asians and decolourised white, length: $c a .11 \mathrm{~cm}$ ) were bundled by a nylon band and kept under a low humidity. NLES-227 (Taiko Oil Chemicals) that contains $27 \mathrm{wt} \%$ of sodium dodecyloxypoly(oxyethylene) sulphate $\left(\mathrm{C}_{12} \mathrm{H}_{25} \mathrm{O}\left(\mathrm{CH}_{2} \mathrm{CH}_{2} \mathrm{O}\right)_{n} \mathrm{SO}_{3} \mathrm{Na}\right.$, mean of $\mathrm{n}$ is ca. 2) was used as an anionic detergent aqueous solution for washing hair.

\subsection{Hair Dyeing}

Dyeing hair was made by each the procedure as follows:

1) Simultaneous Oxidation Dyeing Method<smiles>Oc1cc(O)c2c(c1)O[C@H](c1ccc(O)c(O)c1)C(O)C2</smiles>

(a)<smiles>Oc1cc(O)c2c(c1)O[C@H](c1ccc(O)c(O)c1)[C@H](O)C2</smiles>

(b)<smiles>N[C@@H](Cc1ccc(O)c(O)c1)C(=O)O</smiles>

(c)<smiles>Oc1cc2c(cc1O)C1c3ccc(O)c(O)c3OCC1(O)C2</smiles>

(d)<smiles>Oc1ccc2c(c1)OCC1(O)Cc3cc(O)c(O)cc3C21</smiles>

(e)

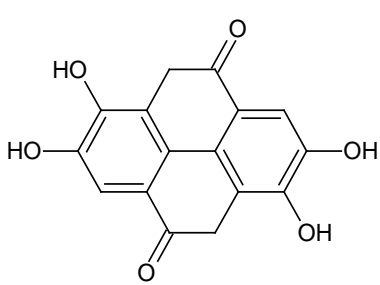

(f)<smiles>O=C(O)/C=C/c1ccc(O)c(O)c1</smiles>
(g)

Figure 1. Chemical structure of bio-catechol materials, (a) (+)-Catechin (Cat), (b) (-)-epicatechin (EC), (c) L-3,4-dihydroxyphenylalanine (DOPA), (d) hematoxylin (HX),

(e) brazilin (BZ), (f) ellagic acid (EA), (g) rosmarinic acid (RA), (h) caffeic acid (CA) and

(i) chlorogenic acid (ChA). 
A human hair sample was immersed into a $10 \mathrm{mM}$ dye precursor phosphate buffer solution with $70 \mathrm{U} \mathrm{ml}^{-1}$ tyrosinase at $\mathrm{pH}=7.0$, into which $\mathrm{O}_{2}$ gas $(100 \mathrm{ml}$ $\mathrm{min}^{-1}$ ) was preliminarily introduced at $30^{\circ} \mathrm{C}$ for over $20 \mathrm{~min}$. The dyebath was shaken at 100 strokes per minute at $30^{\circ} \mathrm{C}$ for 40 min with $\mathrm{O}_{2}$ gas introduced.

2) Post-Oxidation Dyeing Method

After hair was treated in each of the $10 \mathrm{mM}$ dye precursor solution at $30^{\circ} \mathrm{C}$ for $40 \mathrm{~min}$, it was dyed in $70 \mathrm{U} \mathrm{ml}^{-1}$ tyrosinase solution at $\mathrm{pH}=7.0$ at $30^{\circ} \mathrm{C}$ for 40 min with $\mathrm{O}_{2}$ gas introduced. The treatment and dyeing were carried out with the solution shaken at 100 strokes per minute.

The dyed hair was washed with $100 \mathrm{ml}$ of $0.8 \mathrm{wt} \%$ sodium dodecyloxypolyoxyethylene sulphate aqueous solution and rinsed twice with $200 \mathrm{ml}$ of distilled water at $35^{\circ} \mathrm{C}$. The washing and rinsing were carried out with the solution shaken at 100 strokes per minute. The hair was air-dried at room temperature.

\subsection{Measurements}

The colour of hair was measured by a Konica Minolta CM-2600d spectrocolourimeter and the resulting colour was expressed in $L^{*} a^{*} b^{*}$ standard colourimetric system (CIE 1976) in the same method as previous researches [3] [4] [5]. The colour measurements were made employing 10-view angle, CIE standard illuminant $\mathrm{D}_{65}$ and SCI (specular component included) mode. All the reflected lights from the sample including the regular reflection are integrated under the SCI mode. The $L^{*}$ is the lightness index, and $a^{*}$ and $b^{*}$ are the chromaticity coordinates. The positive values of $a^{*}$ indicate reddish colours and the negative values of that indicate greenish ones, and the positive values of $b^{*}$ indicate yellowish and the negative values indicate bluish. The $C^{*}$ is the chroma calculated as $C^{*}=\left\{\left(a^{*}\right)^{2}+\left(b^{*}\right)^{2}\right\}^{1 / 2}$ [6] [7]. The colour difference $\left(\Delta E^{*}\right)$ between the dyed hair and undyed hair was calculated as

$\Delta E^{*}=\left\{\left(L^{*}-L_{0}^{*}\right)^{2}+\left(a^{*}-a_{0}^{*}\right)^{2}+\left(b^{*}-b_{0}^{*}\right)^{2}\right\}^{1 / 2}$, where $L^{*}, a^{*}, b^{*}$ are the values for the dyed hair and $L^{*}, a_{0}{ }_{0}, b^{*}{ }_{0}$ for the undyed hair [6] [7].

The measurements of the ultraviolet-visible (UV-Vis) light absorption spectra for the pigment aqueous solutions were made by a Hitachi U-3900H spectrophotometer at $25^{\circ} \mathrm{C}$. The reaction solution was sampled at several time intervals and diluted by $0.1 \mathrm{M}$ phosphate buffer solution $(\mathrm{pH}=7.0)$ with a dilution ratio $(f)$. The absorbance $(A)$ was normalised to obtain the $f \cdot A$ values for comparison. The $f \cdot A$ value is the quantity that relates to the concentration of pigment formed in the reaction solution.

\section{Results and Discussion}

\subsection{Oxidation of Bio-Catechols and Obtained Pigments}

First, the pigment formation behaviour from the eight kinds of bio-catechols in addition to (+)-catechin was confirmed by oxidising them enzymatically in aqueous solution. This was a preliminary study to know their applicability as dyestuff precursors. The results show that pigments are formed from eight biocatechols except EA. The colours of the formed pigments are different and de- 
pend on the sort of the pigment precursors as described hereinafter. The solubility of EA in water is too low (less than $0.2 \mathrm{mM}$ ) and the pigment formation is poor. Consequently, EA is not able to be used as a dyestuff precursor for hair colouring. The pigment formation behaviours of the other precursors were observed by the UV-Vis absorption spectroscopy.

The colour of Cat and EC solution turns deeper red with time by the enzymatic oxidation. Figure 2 shows the normalised $A$, (as $f \cdot A$ ), spectra calculated from $A$ values for the Cat and EC solution before the oxidation reaction and at 40 min of the reaction time. The absorption signal peak appears at $435 \mathrm{~nm}$ when the enzymatic reaction proceeds. The signal is due to the $o$-benzoquinone form of the pigment (catechinone) as shown in Figure 3 [3]. The reaction produces also minor side products, which are dimer and multimers of Cat. The results show that more catechinone are produced from EC than Cat under the same experimental condition. The peak wavelengths of each spectrum are same, where as the spectrum forms are slightly different. This indicates that the chemical composition of formed pigments from Cat and EC may differ.

Enzymatic oxidation treatment changes the colour of DOPA solution from colourless to yellow, red and black, in this sequence. Figure 4 shows the timecourse of the $f \cdot A$ spectra of DOPA solution. DOPA is a precursor for the insoluble black melanin pigment, which is contained in black hair and the structure is

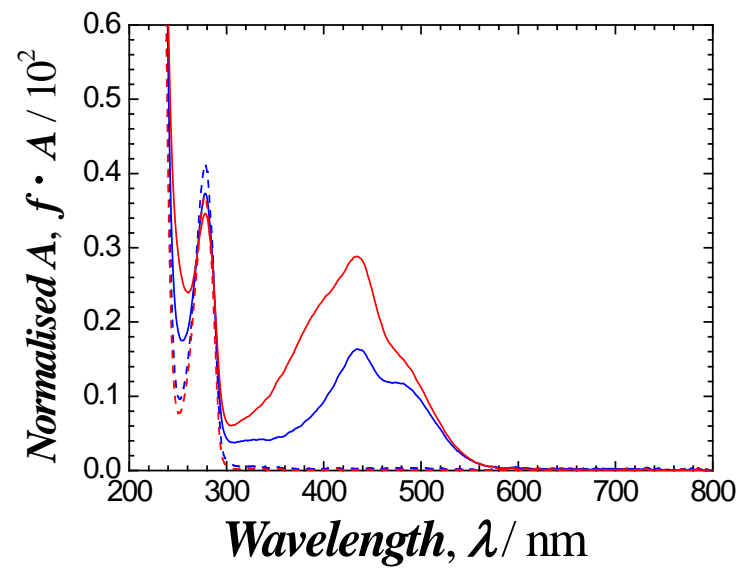

Figure 2. Absorption spectra for the reaction solution of $10 \mathrm{mM}$ Cat (blue line) and 10 mM EC (red line) oxidised with $70 \mathrm{U} \mathrm{ml}^{-1}$ tyrosinase at $\mathrm{pH}=7.0$ and $30^{\circ} \mathrm{C}$ with $\mathrm{O}_{2}$ gas introduced. The curves indicate before (dashed line: ---) and $40 \mathrm{~min}$ after (solid line: the reaction. The absorbance $A$ was normalised to $f \cdot A$.

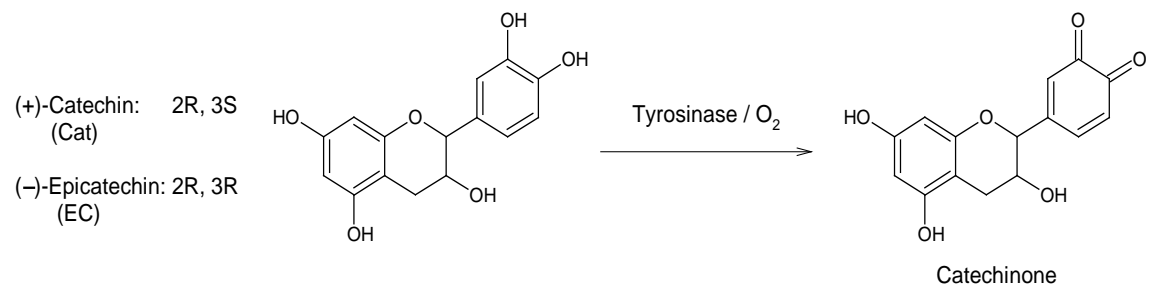

Figure 3. Enzymatic oxidation reaction scheme from (+)-catechin $[2 R, 3 S]$ and (-)-epicatechin $[2 R, 3 R]$ to form catechinone. 


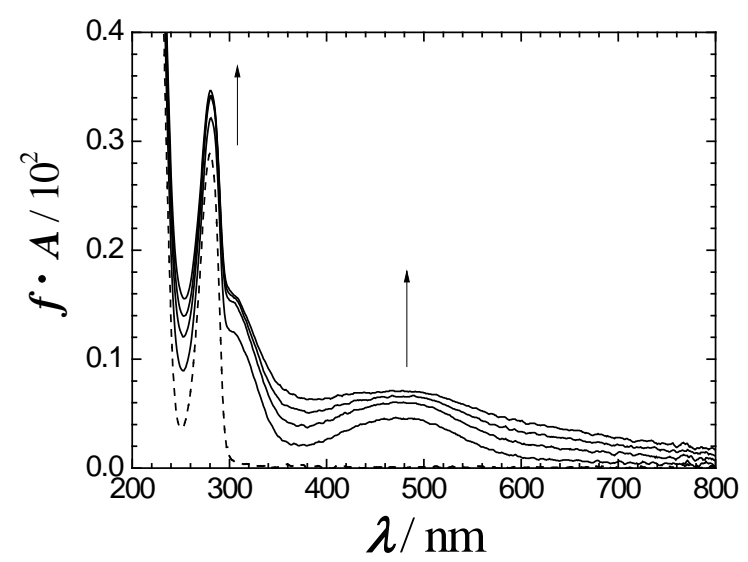

Figure 4. Absorption spectra for the reaction solution of $10 \mathrm{mM}$ DOPA oxidised with 70 $\mathrm{U} \mathrm{ml}^{-1}$ tyrosinase at $\mathrm{pH}=7.0$ and $30^{\circ} \mathrm{C}$ with $\mathrm{O}_{2}$ gas introduced. The curves indicate before (dashed line: ---) and after (solid line: - - ) the reaction and the reaction time intervals are every $10 \mathrm{~min}$ between 0 and $40 \mathrm{~min}$. The absorption signals increase with reaction time as indicated by the direction of the arrows.

complicated [8]. Melanin is synthesised via some oxidative polymerisation processes from tyrosine, which is the precursor substance of DOPA [9] [10] [11]. The change in the signal observed at around $475 \mathrm{~nm}$ in the spectra of DOPA shows the formation of DOPA chrome. The development of the absorbance on whole wavelength corresponds to the chemical conversion from DOPA chrome into 5,6-dihydroxyindole (DHI), indole-5,6-quinone and eumelanin (black melanin) in that order. The reaction pathway between DOPA and indole-5,6-quinone is enzymatic and that between indole-5,6-quinone and eumelanin is non-enzymatic. The pigment products obtained here have probably low molecular weights because they are soluble in the aqueous solution.

Figure 5 exhibits the $f \cdot A$ spectra of $\mathrm{HX}$ and $\mathrm{BZ}$ solution before the oxidation reaction and at $40 \mathrm{~min}$ of the reaction time. The colour of HX solution becomes deeper red by the enzymatic reaction, and the signal peaks at $558 \mathrm{~nm}$ and 440 $\mathrm{nm}$ increase with the $40 \mathrm{~min}$ reaction. This indicates the conversion of HX into hematein as shown in Figure 6 [12]. The chemical structure of BZ is related to that of $\mathrm{HX}$ and is oxidised to deep red brazilein (Figure 6). The signal at $540 \mathrm{~nm}$ for the $\mathrm{BZ}$ solution increases as the reaction proceeds (Figure 5).

RA, CA and ChA are cinnamic acid (3-phenyl-2-propenoic acid) derivatives having the catechol group. Their solutions change in colour as from yellow to black in a similar way by the reaction. Figure 7 indicates the solution $f \cdot A$ spectra before the oxidation reaction and at $40 \mathrm{~min}$ of the reaction time. Their absorbance over $400 \mathrm{~nm}$ increases at $40 \mathrm{~min}$. The absorption signals are due to the production of $o$-benzoquinone, dimer and trimer, of which $\pi$-electron conjugation systems are expanded [13].

Figure 8 summarises all of the $f \cdot A$ spectra between 350 and $800 \mathrm{~nm}$ for the solutions obtained from the bio-catechols after the enzymatic oxidation treatment. The figure shows that the formed pigments from Cat, EC, HX and BZ have large signal peaks and the order of the integrated amount of $f \cdot A$ is $\mathrm{HX}>$ 


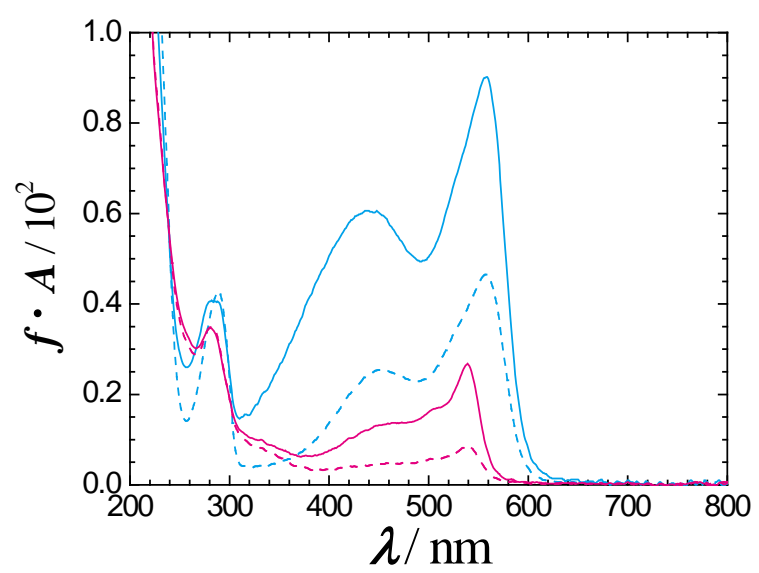

Figure 5. Absorption spectra for reaction solution of $10 \mathrm{mM} \mathrm{HX}$ (cyan line) or $10 \mathrm{mM}$ $\mathrm{BZ}$ (magenta line) oxidised with $70 \mathrm{U} \mathrm{ml}^{-1}$ tyrosinase at $\mathrm{pH}=7.0$ and $30^{\circ} \mathrm{C}$ with $\mathrm{O}_{2}$ gas introduced. The curves indicate before (dashed line: ---) and $40 \mathrm{~min}$ after (solid line: the reaction.

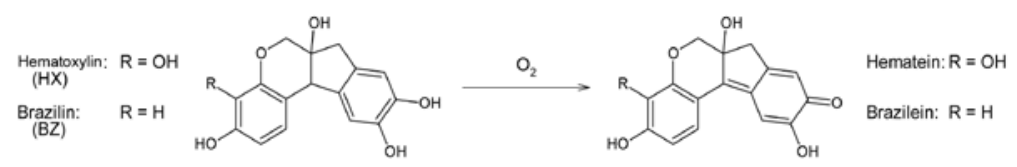

Figure 6. Oxidation reaction from $\mathrm{HX}$ or $\mathrm{BZ}$ to generate hematein or brazilein.

$\mathrm{EC}>\mathrm{BZ}>$ Cat. The other pigments obtained from DOPA, RA, CA and ChA show flat spectra and lower absorbance. The absorption spectrum for the pigment from DOPA solution covers whole of the visible wavelength. It results in black colour.

\subsection{Hair Dyeing by the Bio-Catechol Oxidation Technique}

The dyeability of human hair using Cat, EC, DOPA, HX, BZ, RA, CA and ChA were investigated, from which pigments are obtained by enzymatic oxidation reaction. The dyestuff precursors were oxidised here also enzymatically and hair was treated by the (1) simultaneous oxidation dyeing method or (2) post-oxidation dyeing method at $30^{\circ} \mathrm{C}$ and $\mathrm{pH}=7.0$. Figure 9 and Figure 10 show the photographs of treated hair samples and their resulting colourimetric values, respectively. Hair is very little dyed with RA, CA or ChA by both the enzymatic oxidation dyeing methods as shown in the figures. In contrast, it was found that hair is dyed with EC, DOPA, HX or BZ in addition to Cat by both the enzymatic oxidation dyeing methods. The colourimetric values and colour difference $\Delta E^{*}$ between the undyed and dyed samples for the hair are summarised in Table 1. The obtained colours of hair dyed with Cat, EC, DOPA, HX or BZ by the simultaneous oxidation dyeing method are yellowish brown, yellowish brown, grey, dark yellowish brown or reddish brown, respectively. Those with Cat, EC, DOPA, HX or BZ by post-oxidation dyeing method are yellowish brown, yellowish brown, pale grey, grey or pale brown respectively. They show lower $L^{*}$ values and $\Delta E^{*}$ values for the hair dyed by simultaneous oxidation dyeing 


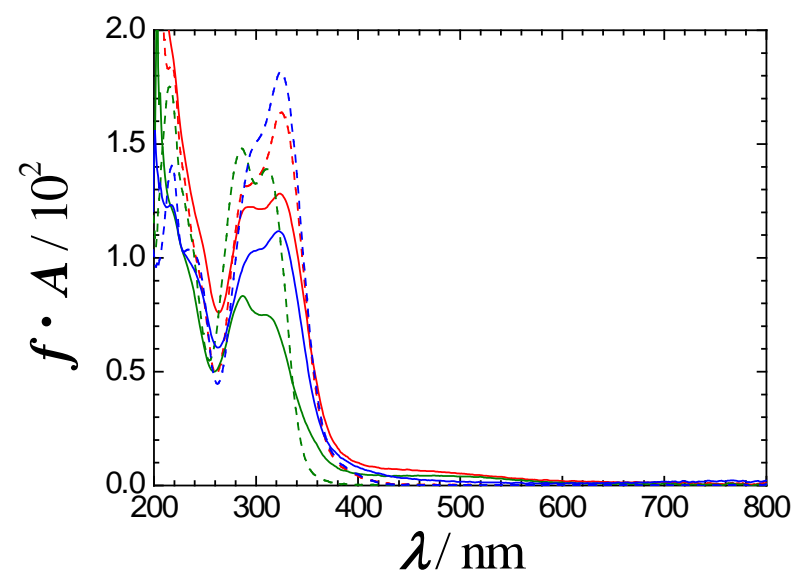

(a)

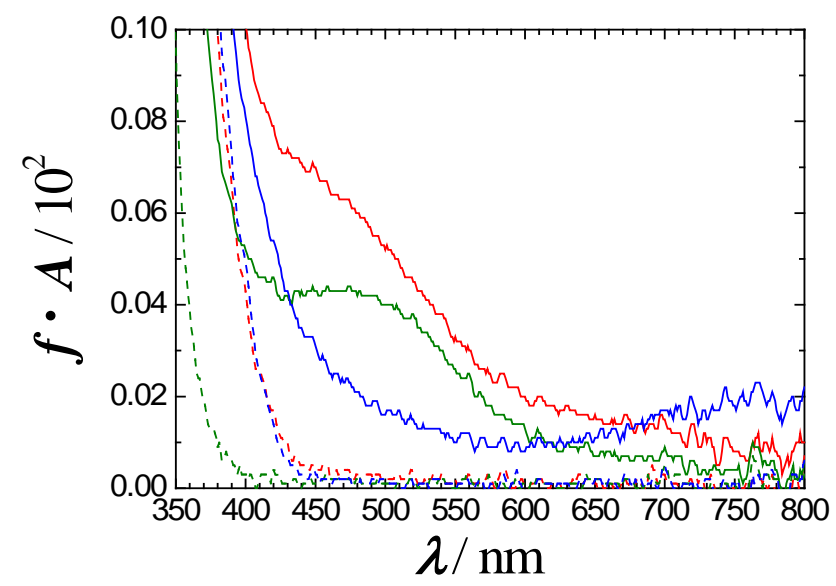

(b)

Figure 7. Overall view (a) and magnified view (b) of the absorption spectra for reaction solution of $10 \mathrm{mM}$ RA (red line), $10 \mathrm{mM} \mathrm{CA}$ (green line) and $10 \mathrm{mM}$ ChA (blue line) oxidised with $70 \mathrm{U} \mathrm{ml}^{-1}$ tyrosinase at $\mathrm{pH}=7.0$ and $30^{\circ} \mathrm{C}$ with $\mathrm{O}_{2}$ gas introduced. The curves indicate before (dashed line: ---) and $40 \mathrm{~min}$ after (solid line: - - ) the reaction.

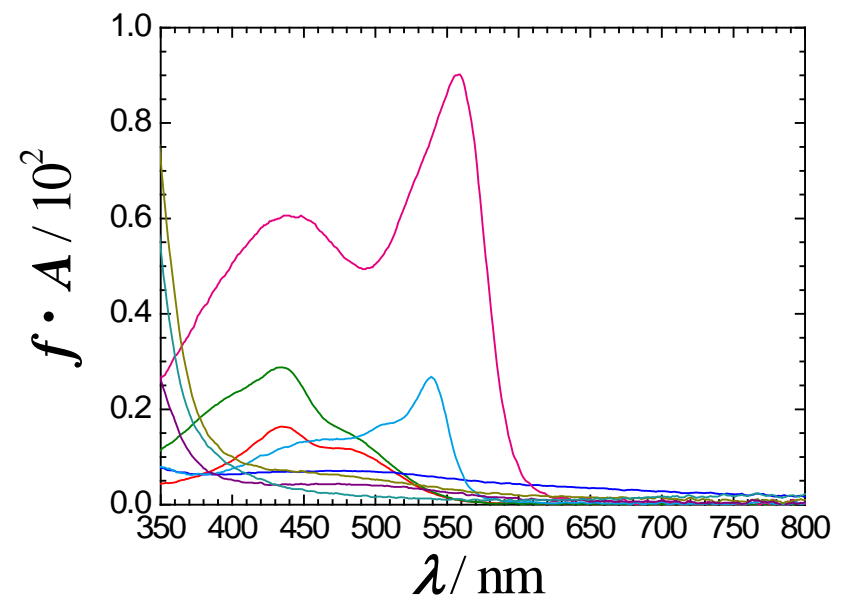

Figure 8. Absorption spectra between 350 and $800 \mathrm{~nm}$ for the reaction solution of $10 \mathrm{mM}$ Cat (red line), EC (green line), DOPA (blue line), HX (magenta line), BZ (cyan line), RA (olive line), CA (purple line) and ChA (pale blue line) oxidised with $70 \mathrm{U} \mathrm{ml}^{-1}$ tyrosinase at $\mathrm{pH}=7.0$ and $30^{\circ} \mathrm{C}$ for $40 \mathrm{~min}$ with $\mathrm{O}_{2}$ gas introduced. 


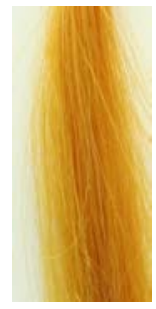

(a)

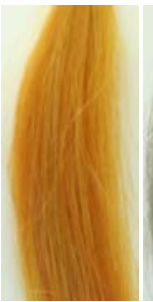

(b)

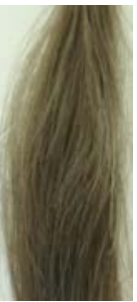

(c)

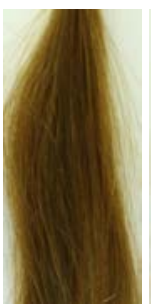

(d)

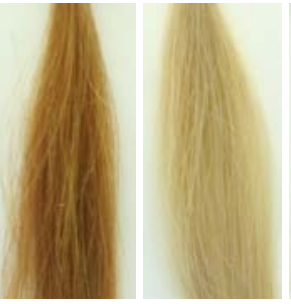

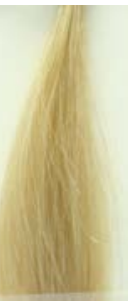

(g)

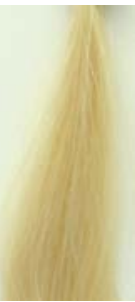

(h)

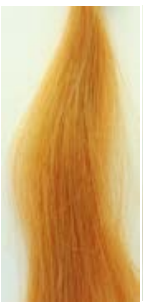

(i)

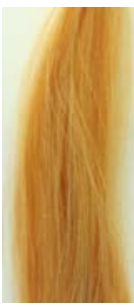

(j)

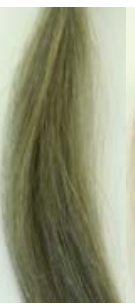

(1) (e)

(f)

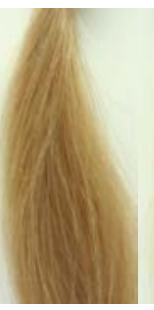

(m) (k)

Figure 9. Photographs of hair samples treated by enzymatic simultaneous oxidation dyeing method (a-h) and enzymatic post-oxidation dyeing method (i-p) by using bio-catechol materials. Used bio-catechols were Cat (a, i), EC (b, j), DOPA (c, k), HX (d, l), BZ (e, $\mathrm{m}), \mathrm{RA}(\mathrm{f}, \mathrm{n}), \mathrm{CA}(\mathrm{g}, \mathrm{o})$ and $\mathrm{ChA}(\mathrm{h}, \mathrm{p})$.

Table 1. The colourimetric values for the hair samples dyed with bio-catechol precursors by simultaneous oxidation and post-oxidation dyeing methods.

\begin{tabular}{|c|c|c|c|c|c|c|c|c|c|c|c|}
\hline \multirow{2}{*}{$\begin{array}{c}\text { Dyeing method } \\
\text { Colourimetric value }\end{array}$} & & \multicolumn{5}{|c|}{$\begin{array}{c}\text { Simultaneous oxidation } \\
\text { dyeing }\end{array}$} & \multicolumn{5}{|c|}{ Post-oxidation dyeing } \\
\hline & & $L^{*}$ & $a^{*}$ & $b^{*}$ & $C^{*}$ & $\Delta E^{* \mathrm{a}}$ & $L^{*}$ & $a^{*}$ & $b^{*}$ & $C^{*}$ & $\Delta E^{* \mathrm{a}}$ \\
\hline \multicolumn{12}{|l|}{ Bio-catechols } \\
\hline$(+)$-Catechin & (Cat) & 58.4 & 16.90 & 53.90 & 56.50 & 33.40 & 54.4 & 18.7 & 37.7 & 42.1 & 26.20 \\
\hline (-)-Epicatechin & (EC) & 58.3 & 16.90 & 45.70 & 48.80 & 27.30 & 62.5 & 15.5 & 40.3 & 43.2 & 20.70 \\
\hline L-3,4-Dihydroxyphenylalanin & (DOPA) & ) 38.6 & 0.890 & 6.27 & 6.33 & 40.50 & 57.6 & 0.810 & 11.2 & 11.2 & 22.50 \\
\hline Hematoxylin & $(\mathrm{HX})$ & 35.1 & 6.22 & 21.30 & 22.20 & 38.70 & 49.4 & -0.690 & 010.6 & 10.6 & 29.30 \\
\hline Brazilin & (BZ) & 49.4 & 12.10 & 25.90 & 28.50 & 25.30 & 57.5 & 7.30 & 18.8 & 20.1 & 18.00 \\
\hline Rosmarinic acid & (RA) & 65.0 & 3.89 & 21.40 & 21.70 & 10.00 & 66.0 & 4.19 & 22.4 & 22.8 & 8.61 \\
\hline Caffeic acid & $(\mathrm{CA})$ & 65.8 & 3.85 & 22.90 & 23.20 & 8.48 & 64.1 & 6.11 & 22.6 & 23.4 & 10.30 \\
\hline Chlorogenic acid & (ChA) & 70.5 & 4.18 & 25.70 & 26.10 & 3.03 & 70.9 & 4.25 & 25.8 & 26.1 & 2.70 \\
\hline
\end{tabular}

a: Colour difference between the dyed hair and undyed hair, $\Delta E^{*}=\left\{\left(L^{*}-L_{0}^{*}\right)^{2}+\left(a^{*}-a_{0}^{*}\right)^{2}+\left(b^{*}-\right.\right.$ $\left.\left.b^{*}{ }_{0}\right)^{2}\right\}^{1 / 2}$, where $L^{*}, a^{*}, b^{*}$ are for the dyed hair and $L^{*}, a^{*}{ }_{0}, b^{*}{ }_{0}$ for the undyed hair. $L^{*}{ }_{0}=73.4, a^{*}{ }_{0}=4.16$, $b^{*}=26.8, C^{*}=27.2$.

method are larger than those obtained by post-oxidation dyeing method. It can be said from the results that Cat, EC, DOPA, HX and BZ are available as the dyestuff precursors for hair dyeing and the simultaneous method is superior to the post-oxidation method in the enzymatic dyeing techniques. The continuous supply of the precursors from dyebath into hair during the oxidation and dyeing processes in the simultaneous method may contribute the higher dyeability.

The $\Delta E^{*}$ for DOPA system obtained by the simultaneous method differs larg- 
est from that obtained by the post-oxidation method. It is assumed that DOPA oxidised to DHI in the bulk solution penetrates into hair more easily in the simultaneous method, because DHI is charged a little negatively. Indeed, there are some approaches to dye hair using DHI as a raw material [14] [15]. The dyeing results are similar to ours.

Cat, EC, HX and BZ (except DOPA), which show higher dyeability for hair, have chroman (3,4-dihydro-2H-1-benzopyran) structure with catechol part as shown in Figure 11. The dyestuff precursors having both the catechol and chroman structures give the pigments that show higher light absorbability as

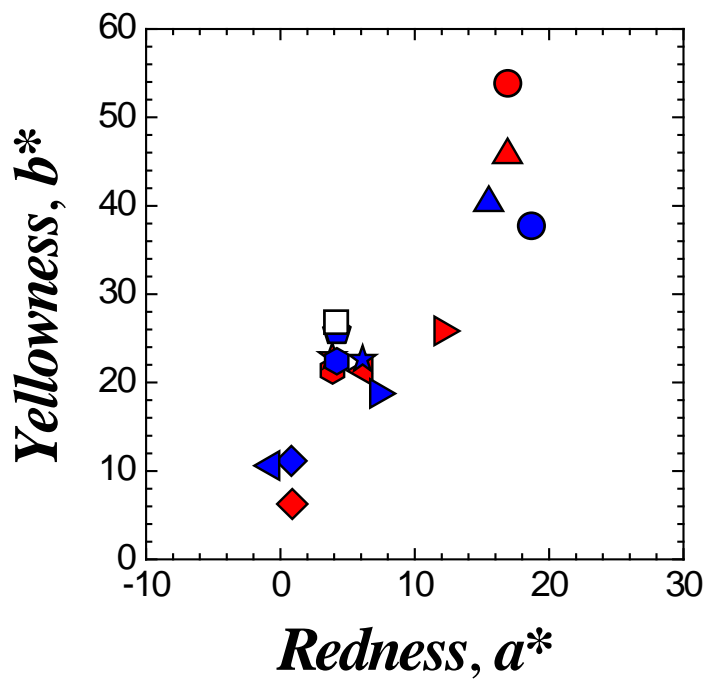

(a)

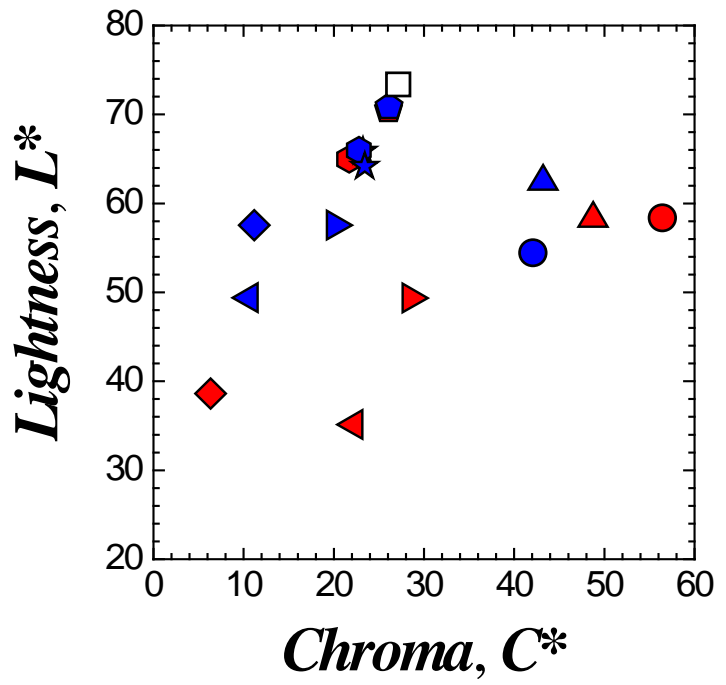

(b)

Figure 10. Colour measurement results of hair samples undyed ( $\square$ ) and dyed by simultaneous enzymatic oxidation dyeing method (red symbols) or post-enzymatic oxidation dyeing method (blue symbols) with bio-catechol materials. Used bio-catechols are Cat

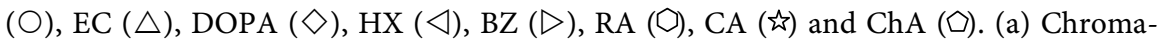
ticity coordinates relationships $\left(a^{*}-b^{*}\right)$ and (b) chroma-lightness index relationships $\left(C^{*}-L^{*}\right)$. 
<smiles>Oc1cc(O)c2c(c1)O[C@H](c1ccc(O)c(O)c1)C(O)C2</smiles>

(a)

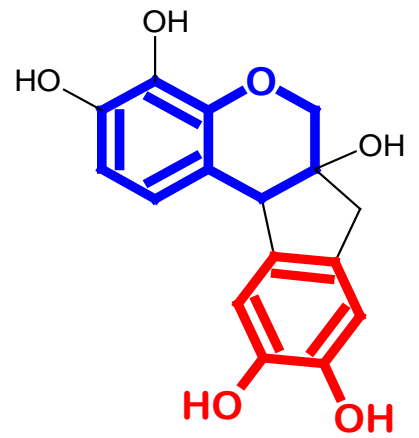

(c)<smiles>Oc1cc(O)c2c(c1)O[C@H](c1ccc(O)c(O)c1)[C@H](O)C2</smiles>

(b)

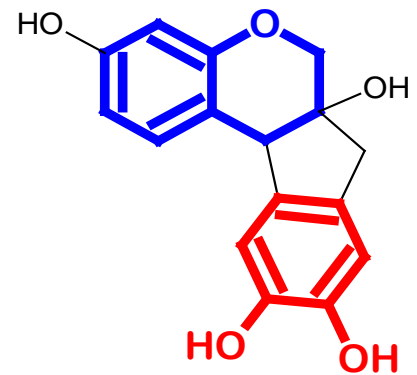

(d)

Figure 11. Chemical structures of Cat (a); EC (b); HX (c) and BZ (d) showing the catechol structure in red and chroman structure in blue.

discussed before at $\$ 3.1$. Such the chemical structures play a key role for dyeing hair. The result that while DOPA is similar in the whole chemical structure to caffeic acid, the hair dyeabilities are different, is interesting. Here, the difference in the structures such as with or without the amino group and double bond is essential. It is suggested that the differences of the dyeability between the above five kinds of bio-catechols and the other precursors and also between the dyeing methods may be caused by the differences in their oxidation reactivity, the light absorbability of the formed dyestuffs, the dyestuff compositions, their adsorption behaviour onto hair and so on.

\section{Conclusion}

Hair is dyed by utilising enzymatic oxidation of bio-catechols, (+)-catechin, (-)-epicatechin, L-3, 4-dihydroxyphenylalanine, hematoxylin and brazilin. Both of the simultaneous oxidation and post-oxidation dyeing method are applicable to the hair colouring and deeper colours are obtained by the former one. The techniques give a variety of colours of dyed hair like yellowish brown, reddish brown, pale brown and grey. The hair dyed with (+)-catechin by the simultaneous enzymatic oxidation dyeing method shows the highest chroma $\left(C^{*} \sim 56\right)$ and that with hematoxylin shows the lowest lightness $\left(L^{*} \sim 35\right)$.

\section{Acknowledgements}

This study was financially supported partly by the Japan Society for the Promotion of Science as Grant-in-Aid for Young Scientists (B) (No. 15K16185), the 
Promotion and Mutual Aid Corporation for Private Schools of Japan as Young Researchers Incentives of the Science Research Promotion Fund and The Cosmetology Research Foundation.

\section{References}

[1] Helaskoski, E., Suojalehto, H., Virtanen, H., Airaksinen, L., Kuuliala, O., AaltoKorte, K. and Pesonen, M. (2014) Occupational Asthma, Rhinitis, and Contact Urticaria Caused by Oxidative Hair Dyes in Hairdressers. Annals of Allergy, Asthma \& Immunology, 112, 46-52. https://doi.org/10.1016/j.anai.2013.10.002

[2] Gupta, M., Mahajan, V.K., Mehta, K.S. and Chauhan, P.S. (2015) Hair Dye Dermatitis and $p$-Phenylenediamine Contact Sensitivity: A Preliminary Report. Indian Dermatology Online Journal, 6, 241-246. https://doi.org/10.4103/2229-5178.160253

[3] Yasunaga, H., Takahashi, A., Ito, K., Ueda, M. and Urakawa, H. (2012) Hair Dyeing by Using Catechinone Obtained from (+)-Catechin. Journal of Cosmetics, Dermatological Sciences and Applications, 2, 158-163. https://doi.org/10.4236/jcdsa.2012.23031

[4] Matsubara, T., Taniguchi, S., Morimoto, S., Yano, A., Hara, A., Wataoka, I., Urakawa, H. and Yasunaga, H. (2015) Relationship between Dyeing Condition and Dyeability in Hair Colouring by Using Catechinone Prepared Enzymatically or Chemically from (+)-Catechin. Journal of Cosmetics, Dermatological Sciences and Applications, 5, 94-106. https://doi.org/10.4236/jcdsa.2015.52012

[5] Matsubara, T., Seki, C. and Yasunaga, H. (2016) The Relationships between Dyeing Methods and Dyeability in Hair Colouring by Utilising Enzymatic Oxidation of (+)-Catechin. American Journal of Plant Sciences, 7, 1058-1066. https://doi.org/10.4236/ajps.2016.77101

[6] Robertson, A.R. (1977) The CIE 1976 Color-Difference Formulae. Color Research \& Application, 2, 7-11. https://doi.org/10.1002/j.1520-6378.1977.tb00104.x

[7] Commission Internationale de l'Eclairage (2007) Colorimetry-Part 4: CIE 1976 L*a*b* Colour Space, CIE S 014-4/E: 2007 (ISO 11664-4:2008(E)), Switzerland.

[8] Robbins, C.R. (2012) Chemical and Physical Behavior of Human Hair. 5th Edition, Springer-Verlag, Berlin, Heidelberg. https://doi.org/10.1007/978-3-642-25611-0

[9] Korner, A. and Pawelek, J. (1982) Mammalian Tyrosinase Catalyzes Three Reactions in the Biosynthesis of Melanin. Science, 217, 1163-1165. https://doi.org/10.1126/science.6810464

[10] Hearing V.J. and Tsukamoto, K. (1991) Enzymatic Control of Pigmentation in Mammals. The FASEB Journal, 5, 2902-2909.

[11] Rodríguez-López, J.N., Tudela, J., Varón, R., García-Carmona, F. and GarcíaCánovas, F. (1992) Analysis of a Kinetic Model for Melanin Biosynthesis Pathway. The Journal of Biological Chemistry, 267, 3801-3810.

[12] Marshall, P.N. and Horobin, R.W. (1972) The Oxidation Products of Haematoxylin and their Role in Biological Staining. The Histochemical Journal, 4, 493-503. https://doi.org/10.1007/BF01011129

[13] Rompel, A., Fischer, H., Meiwes, D., Büldt-Karentzopoulos, K., Magrini, A., Eicken, C., Gerdemann, C. and Krebs, B. (1999) Substrate Specificity of Catechol Oxidase from Lycopus europaeus and Characterization of the Bioproducts of Enzymic Caffeic Acid Oxidation. The FEBS Letters, 445, 103-110. https://doi.org/10.1016/S0014-5793(99)00106-4

[14] Brown, K., Mayer, A., Murphy, B., Schultz, T. and Wolfram, L. (1989) Hair Color- 
ing by Melanin Precursors: A Novel System for Imparting Durable Yet Reversible Color Effects. Journal of the Society of Cosmetic Chemists, 40, 65-74.

[15] Nakamura, Y., Yamanaka, H., Hata, Y., Ebato, A. and Koike, K. (2012) Development of the Novel Hair Coloring System Using Enzymatically-Prepared Melanin Precursors by Aspergillus oryzae Tyrosinase. Seibutsu-Kogaku Kaishi, 90, 115-121. (In Japanese)

Submit or recommend next manuscript to SCIRP and we will provide best service for you:

Accepting pre-submission inquiries through Email, Facebook, LinkedIn, Twitter, etc. A wide selection of journals (inclusive of 9 subjects, more than 200 journals)

Providing 24-hour high-quality service

User-friendly online submission system

Fair and swift peer-review system

Efficient typesetting and proofreading procedure

Display of the result of downloads and visits, as well as the number of cited articles Maximum dissemination of your research work

Submit your manuscript at: http://papersubmission.scirp.org/

Or contact ajps@scirp.org 